\title{
EP4 activation ameliorates liver ischemia/reperfusion injury via ERK1/2-GSK3ß-dependent MPTP inhibition
}

\author{
LIN-LIN CAI ${ }^{1,2^{*}}$, HAI-TAO XU ${ }^{1 *}$, QI-LONG WANG ${ }^{1 *}$, YA-QING ZHANG $^{1}$, WEI CHEN $^{1}$, \\ DONG-YU ZHENG ${ }^{1}$, FANG LIU ${ }^{3}$, HONG-BIN YUAN ${ }^{1}$, YONG-HUA LI ${ }^{1}$ and HAI-LONG FU ${ }^{1}$ \\ ${ }^{1}$ Department of Anesthesiology, Changzheng Hospital, Second Military Medical University, Shanghai 200003; \\ ${ }^{2}$ Department of Anesthesiology, Shanghai First Maternity and Infant Hospital, School of Medicine, \\ Tongji University, Shanghai 201204; ${ }^{3}$ National Key Laboratory of Medical Immunology and Department of Immunology, \\ Second Military Medical University, Shanghai 200433, P.R. China
}

Received October 12, 2019; Accepted February 4, 2020

DOI: $10.3892 / \mathrm{ijmm} .2020 .4544$

\begin{abstract}
Prostaglandin E receptor subtype 4 (EP4) is widely distributed in the heart, but its role in hepatic ischemia/reperfusion (I/R), particularly in mitochondrial permeability transition pore (MPTP) modulation, is yet to be elucidated. In the present study, an EP4 agonist (CAY10598) was used in a rat model to evaluate the effects of EP4 activation on liver $\mathrm{I} / \mathrm{R}$ and the mechanisms underlying this. $\mathrm{I} / \mathrm{R}$ insult upregulated hepatic EP4 expression during early reperfusion. In addition, subcutaneous CAY10598 injection prior to the onset of reperfusion significantly increased hepatocyte cAMP concentrations and decreased serum ALT and AST levels and necrotic and apoptotic cell percentages,
\end{abstract}

Correspondence to: Professor Hai-Long Fu or Professor Yong-Hua Li, Department of Anesthesiology, Changzheng Hospital, Second Military Medical University, 415 Fengyang Road, Shanghai 200003, P.R. China E-mail: fuhailong1979@163.com

E-mail: liyonghua1207@smmu.edu.cn

${ }^{*}$ Contributed equally

Abbreviations: EP, prostaglandin E receptor; PGE2, prostaglandin E2; COX-2, cyclooxygenase-2; AA, arachidonic acid; MPTP, mitochondrial permeability transition pore; I/R, ischemia/reperfusion; CATR, carboxyatractyloside; CAY, CAY10598; ALT, alanine aminotransferase; AST, aspartate aminotransferase; PKA, protein kinase A; Akt, protein kinase B; GSK3 $\beta$, glycogen synthase kinase $3 \beta$; ATP, adenosine triphosphate; PI3K, phosphoinositide 3'-OH kinase; ERK1/2, extracellular signal-regulated protein kinase 1/2; RISK, reperfusion injury salvage kinase; SAFE, survivor activating factor enhancement; JAK, janus kinase; STAT, signal transducer and activator of transcription; ROS, reactive oxygen species; H\&E, hematoxylin and eosin; TUNEL, terminal deoxynucleotidyl transferase-mediated dUTP nick-end labeling; CRC, calcium retention capacity; cAMP, cyclic adenosine monophosphate; TNF- $\alpha$, tumor necrosis factor- $\alpha$

Key words: ischemia/reperfusion injury, mitochondria, signal transduction, prostaglandin $\mathrm{E}$ receptor, liver after $6 \mathrm{~h}$ of reperfusion. Moreover, CAY10598 protected mitochondrial morphology, markedly inhibited mitochondrial permeability transition pore (MPTP) opening and decreased liver reactive oxygen species levels. This occurred via activation of the ERK1/2-GSK3 $\beta$ pathway rather than the janus kinase (JAK)2-signal transducers and activators of transcription (STAT)3 pathway, and resulted in prevention of mitochondria-associated cell injury. The MPTP opener carboxyatractyloside (CATR) and the ERK1/2 inhibitor PD98059 also partially reversed the protective effects of CAY10598 on the liver and mitochondria. The current findings indicate that EP4 activation induces ERK1/2-GSK3 $\beta$ signaling and subsequent MPTP inhibition to provide hepatoprotection, and these observations are informative for developing new molecular targets and preventative therapies for $\mathrm{I} / \mathrm{R}$ in a clinical setting.

\section{Introduction}

Ischemia/reperfusion (I/R) injury is a common clinical pathological phenomenon that may occur in a wide range of clinical settings, including body trauma with hemorrhagic shock, cardiac coronary ischemia, cardiac cardiopulmonary bypass surgery, partial hepatectomy and liver and kidney transplantation, and it may significantly influence disease prognosis (1). Previous studies have revealed that mitochondrial permeability transition pore (MPTP) opening serves as a key nodal event mediating cell necrosis during early reperfusion and inducing further mitochondrial-related apoptosis (2,3). MPTP opening is regulated by multiple intracellular signal transduction pathways (4-6). It has previously been reported that cyclooxygenase-2 (COX-2) inhibitor pretreatment decreases MPTP opening and liver damage in a rat I/R model (7). However, inhibiting COX-2 signaling may aggravate ischemic injury in myocardial and renal I/R $(8,9)$, which may be associated with the ability of COX-2 to regulate numerous prostaglandins and receptors downstream.

The COX-2 signaling pathway is activated during I/R to catalyze the production of prostaglandin E2 (PGE2) from arachidonic acid (AA). As a member of the eicosanoid family, PGE2 is an endogenous lipid mediator (10) that 
binds to four specific $G$ protein-coupled receptors on the cell membrane [prostaglandin E receptor subtype 1 (EP1), EP2, EP3 and EP4] (11). Of these receptors, EP4 is the most widely distributed among tissues and is involved in various pathophysiological processes (12-17). After activation, EP4 is coupled primarily to intracellular stimulated Gs-proteins and upregulates intracellular cyclic adenosine monophosphate (cAMP) levels (18). Changes in cAMP concentrations further influence intracellular cAMP-dependent protein kinases and their downstream signals, such as cAMP-protein kinase A (PKA), phosphatidylinositol 3-kinase (PI3K) and extracellular signal-regulated protein kinase (ERK) $1 / 2$, to produce corresponding biological effects $(11,13)$. Recently, Kuzumoto et al (12) reported that EP4 activation protects the mouse liver from ischemic injury by mediating inflammation during early reperfusion. Nishizawa et al (19) demonstrated that the PGE2/EP4 pathway is enhanced during hepatic I/R in mice and is closely associated with liver injury and repair. Additionally, the PGE2/EP4 axis has been revealed to serve as a homeostatic mechanism that regulates endoplasmic reticulum stress and autophagy in liver transplant recipients (20). However, the full mechanism underlying EP4 signaling in hepatic I/R modulation, particularly the role of EP4 in mitochondrial function, is yet to be elucidated. In our preliminary study (supplementary data), it was revealed that the mRNA expression of EP4 is significantly upregulated in a rat liver I/R model and downregulated by COX-2 inhibition preconditioning, after $2 \mathrm{~h}$ of reperfusion (Fig. S1). Further studies on human hepatic specimens indicated that EP4 expression was significantly higher in transplant allografts that underwent $\sim 20 \mathrm{~min}$ of warm ischemia, $6 \mathrm{~h}$ of cold ischemia and $60 \mathrm{~min}$ of reperfusion compared with non-ischemic liver specimens (Fig. S2). Considering that EP4 is a PGE2 receptor and a regulatory product downstream of $\mathrm{COX}-2$, it was hypothesized that EP4 influences COX-2-associated MPTP modulation during I/R. Therefore, the present study was designed to further investigate the role and mechanism underlying the action of EP4 in MPTP modulation and hepatic I/R.

\section{Materials and methods}

Animals. A total of 132 Male Sprague-Dawley rats (6 weeks old) that weighed 200-220 g were purchased from Sino-British SIPPR/BK Lab Animal Ltd. (Shanghai, China). The animals were housed in standard cages and maintained under standard conditions at a constant room temperature of $20-25^{\circ} \mathrm{C}$, a humidity of $40-70 \%$ and a $12 \mathrm{~h} / 12 \mathrm{~h}$ light/dark cycle, with unrestricted access to food and water. All experiments were performed in accordance with the National Institutes of Health Guide for the Care and Use of Laboratory Animals and were approved by the Changzheng Hospital Ethics Committee [approval number, CZEC (2015)-01].

Hepatic I/R injury model. A rat model was constructed using $70 \%$ partial hepatic ischemia for $60 \mathrm{~min}$ as described previously (21-24). Briefly, rats were fasted for $12 \mathrm{~h}$ before surgery and anesthetized by intraperitoneal (i.p.) injection of $40 \mathrm{mg} / \mathrm{kg}$ pentobarbital. After midline laparotomy, the interlobular ligaments were dissected. The left hepatoduodenal ligament containing the hepatic artery, portal vein and bile duct leading to the left and median lobe was clamped in the liver hilum using a microvascular clamp for $60 \mathrm{~min}$. Reperfusion was initiated by clamp removal. Sham-operated rats underwent the same surgical procedures but without vascular occlusion. The animals were sacrificed by an intraperitoneal injection of sodium pentobarbital $(100 \mathrm{mg} / \mathrm{kg})$ at 2 or $6 \mathrm{~h}$ after reperfusion. Death of the rats was verified by a combination of criteria, including lack of pulse, breathing, corneal reflex, response to a firm toe pinch and graying of the mucous membranes. Liver and serum samples were collected for further analysis.

Experimental protocol. To increase EP4 activity, a dose of $0.1,0.5,1$ or $10 \mathrm{mg} / \mathrm{kg}$ of an EP4 agonist (CAY10598 [CAY]; Cayman Chemical Company) was administered subcutaneously to animals $0,0.5$ and $2.5 \mathrm{~h}$ prior to the onset of liver reperfusion. To increase MPTP susceptibility, a single dose of carboxyatractyloside (CATR; $5 \mathrm{mg} / \mathrm{kg}$, Sigma-Aldrich; Merck KGaA) was dissolved in $0.9 \%$ saline and then administered intraperitoneally to animals $30 \mathrm{~min}$ prior to the $60 \mathrm{~min}$ ischemic insult. Additionally, to inhibit ERK1/2 activity, rats received an intraperitoneal injection of an ERK1/2 inhibitor [PD98059 (PD), Cell Signaling Technology, Inc.], 5 mg/kg dissolved in dimethyl sulfoxide (DMSO) (Cell Signaling Technology, Inc.), 30 min prior to the onset of liver ischemia. The sham and I/R animals received the same volume of the respective vehicles.

Histological assays. Liver samples were fixed in $4 \%$ formaldehyde/phosphate-buffered saline overnight at $4^{\circ} \mathrm{C}$. The samples were dehydrated and embedded in paraffin. Hepatocellular necrosis was calculated in hematoxylin and eosin (H\&E)-stained tissue using a semi-quantitative scale, as previously described (21). Briefly, for each H\&E-stained tissue sample, a total of 30 randomly selected high-power visual fields (magnification, $\mathrm{x} 400$ ) were analyzed in a blinded fashion to determine the percentage of necrotic cells. In the current study, only grade 3 severe injury with hepatic cord disintegration was categorized as necrosis (21).

To evaluate apoptosis, terminal deoxynucleotidyl transferase-mediated dUTP nick-end labeling (TUNEL) staining was also performed using a commercial kit from Roche Diagnostics, according to the manufacturer's instructions. Briefly, paraffin-embedded tissue sections were dewaxed by heating at $60^{\circ} \mathrm{C}$ followed by washing in xylene, rehydration using a graded series of ethanol $(100,95,90,80$ and $70 \%$ ) and double-distilled water, and then pretreatment with proteinase-k. Endogenous peroxidase activity was blocked by immersing in $3 \% \mathrm{H}_{2} \mathrm{O}_{2}$ in methanol for $10 \mathrm{~min}$ at room temperature. TUNEL reaction mixture and Converter-POD were then added, and incubated in a humidified atmosphere for 60 and $30 \mathrm{~min}$ at $37^{\circ} \mathrm{C}$ in the dark, respectively. Each slice was stained using DAB for $10 \mathrm{~min}$ at room temperature, and liver cell apoptosis was observed under light microscopy. In each section, areas without significant necrosis in 10 different visual fields (magnification, x400) were observed and analyzed for TUNEL-positive cells. The TUNEL index was calculated by counting the total nuclei and cells with brown nuclei and using the following formula: [(number of stained cells)/(number of stained cells + number of unstained cells)] x100. Six sections of each tissue sample were analyzed for each group. 
For the immunohistochemical analysis of EP4, liver tissue sections (5- $\mu \mathrm{m}$ thick) were then immunostained using the EnVision method (DakoCytomation; Agilent Technologies, Inc.) according to the manufacturer's instructions. Briefly, tissue sections were pre-treated for $10 \mathrm{~min}$ with peroxidase-blocking reagent (Dako; Agilent Technologies, Inc.) to suppress endogenous peroxidase and pseudoperoxidase activity at room temperature, washed again in phosphate-buffered saline(PBS) and incubated for $1 \mathrm{~h}$ at $37^{\circ} \mathrm{C}$ in a humid chamber with the anti-EP4 polyclonal antibody (1:100; cat. no. SC-20677; Santa Cruz Biotechnology, Inc.). The slides were rinsed twice and then incubated for $60 \mathrm{~min}$ with goat anti-mouse immunoglobulins conjugated to a peroxidase-labeled polymer (1:500; cat. no. P0447; DAKO EnVision ${ }^{\mathrm{TM}}+$ System; Dako; Agilent Technologies, Inc.) at room temperature. After washing, cells were treated with 3,3'-diaminobenzidine (Sigma-Aldrich; Merck $\mathrm{KGaA}$ ) as a chromogen substrate for $10 \mathrm{~min}$ at room temperature. Slides were then washed again in PBS and counterstained with hematoxylin for $2 \mathrm{~min}$ at room temperature. Sections stained with H\&E were used for comparison and compared using a light microscope with a magnification of $\mathrm{x} 400$.

Western blot analysis. The levels of EP4 (Santa Cruz Biotechnology, Inc.), ERK1/2, phosphorylated (p-) ERK1/2, janus kinase 2 (JAK2), p-JAK2, signal transducer and activator of transcription 3 (STAT3), p-STAT3, glycogen synthase kinase-3 $\beta$ (GSK3 $\beta$ ) and p-GSK3 $\beta$ (Ser9; Cell Signaling Technology, Inc.) were evaluated in rat liver lysates using western blot analysis, as previously reported (25). Briefly, liver tissues were homogenized in RIPA lysis buffer (Wuhan Servicebio Technology Co., Ltd.), followed by centrifugation at $12,000 \times \mathrm{g}$ for $15 \mathrm{~min}$ at $4{ }^{\circ} \mathrm{C}$. The bicinchoninic acid method was used for quantitative analysis the protein samples. A total of $40 \mu \mathrm{g}$ protein was applied to each lane and separated via $10 \%$ SDS-PAGE before being transferred onto PVDF membranes. A total of $5 \%$ bovine serum albumin (Sigma-Aldrich; Merck KGaA) and TBS with 0.1\% Tween-20 (PBST) was used to block the unspecific binding of antibodies for $2 \mathrm{~h}$ at $4^{\circ} \mathrm{C}$. Then, blots were incubated with the following primary antibodies: EP4 (1:1,000; cat. no. SC-20677; Santa Cruz Biotechnology, Inc.), ERK1/2 (1:1,000; cat. no. 4695; Cell Signaling Technology, Inc.), p-ERK1/2 (1:2,000; cat. no. 4370; Cell Signaling Technology, Inc.), JAK2 (1:1,000; cat. no. 3230; Cell Signaling Technology, Inc.), p-JAK2 (1:1,000; cat. no. 3776; Cell Signaling Technology, Inc.), STAT3 (1:1,000; cat. no. 30835; Cell Signaling Technology, Inc.), p-STAT3 (1:2,000; cat. no. 9145; Cell Signaling Technology, Inc.), GSK3 $\beta$ (1:1,000; cat. no. 5676; Cell Signaling Technology, Inc.), p-GSK3 $\beta$ (1:1,000; cat. no. 9322; Cell Signaling Technology, Inc.) and GAPDH (1:1,000; cat. no. 5174; Cell Signaling Technology, Inc.), overnight at $4^{\circ} \mathrm{C}$. Blots were then incubated with a goat-anti-rabbit IgG-HRP $(1: 2,000$; cat. no. 7074; Cell Signaling Technology, Inc.) for $1.5 \mathrm{~h}$ at room temperature and washed three times with TBST. An enhanced chemiluminescence (ECL) western blotting detection reagent (cat. no. 34076; Thermo Fisher Scientific, Inc.) was used for visualization. A digital gel image analysis system (model GIS-1000; Tanon) were used to evaluate the specific signals and the corresponding band intensities.
Plasma biochemical assays. Serum alanine aminotransferase (ALT) and aspartate aminotransferase (AST) levels were determined after 2 and $6 \mathrm{~h}$ of reperfusion using an AutoAnalyzer (H-7600, Hitachi Ltd.).

Evaluation of tissue reactive oxygen species (ROS) levels. Liver tissue were collected after 2 and $6 \mathrm{~h}$ of reperfusion. Tissue ROS levels were measured using a ROS enzyme-linked immunosorbent assay (ELISA) kit (Cell Signaling Technology, Inc.) according to the manufacturer's instructions. The results are expressed as relative fluorescence units (U/ml).

Mitochondrial isolation and calcium retention capacity $(C R C)$ assessment. Mitochondria were isolated in liver tissue at 2 and $6 \mathrm{~h}$ of reperfusion using differential centrifugation at $4^{\circ} \mathrm{C}$ as previously described (26). Briefly, the fresh liver tissues $(1 \mathrm{~g})$ were homogenized with $8 \mathrm{ml}$ of isolation buffer A (ISA) containing $220 \mathrm{mmol} / 1 \mathrm{~d}$-mannitol, $70 \mathrm{mmol} / 1$ sucrose, $10 \mathrm{mmol} / 1 \mathrm{Tris}-\mathrm{HCl}$, $1 \mathrm{mmol} / \mathrm{l}$ EGTA and $0.4 \%$ bovine serum albumin (pH 7.4). The homogenates were centrifuged at $850 \mathrm{x} \mathrm{g}$ for $10 \mathrm{~min}$ to collect supernatants, followed by centrifugation at $10,000 \mathrm{x} g$ for an additional $10 \mathrm{~min}$. The mitochondrial pellet was resuspended in a final washing isolation buffer B containing $220 \mathrm{mmol} / \mathrm{l}$ d-mannitol, $70 \mathrm{mmol} / \mathrm{l}$ sucrose and $10 \mathrm{mmol} / \mathrm{l}$ Tris- $\mathrm{HCl}$ (pH 7.4). Protein concentration was determined via the biuret method and calibrated with bovine serum albumin (BSA). A CRC assay was used to evaluate MPTP susceptibility, which was adapted from a previously described method (27). CRC is defined as the amount of $\mathrm{Ca}^{2+}$ required to trigger mass $\mathrm{Ca}^{2+}$ release from isolated liver mitochondria. The extramitochondrial $\mathrm{Ca}^{2+}$ concentration was recorded using a fluorescence microplate reader controlled by SoftMax Pro 4.8 software (Molecular Devices, LLC) in the presence of the Calcium Green-5N molecular probe $(1 \mu \mathrm{mol} / 1$, Invitrogen; Thermo Fisher Scientific, Inc.), with excitation and emission wavelengths of 500 and $530 \mathrm{~nm}$, respectively (7). The fluorescence scan interval was set at $12 \mathrm{sec}$.

Electron microscopy. Electron microscopy was used to examine the ultrastructure of the hepatocytes in liver tissue samples after $6 \mathrm{~h}$ of reperfusion. Briefly, the liver samples were fixed in a $1 \%$ osmic acid fixative solution (Wuhan Servicebio Technology Co.,Ltd.) at $4^{\circ} \mathrm{C}$ for $3 \mathrm{~h}$ and then washed with phosphate-buffered saline (PBS) three times at $4^{\circ} \mathrm{C}$ for $30 \mathrm{~min}$. Dehydration was carried out in graded ethanol solutions (50,70 and 90\%), in a $90 \%$ solution (ethanol:acetone; $1: 1 ; \mathrm{v} / \mathrm{v}$ ) and finally in a $90 \%$ acetone solution at $4^{\circ} \mathrm{C}$ for $20 \mathrm{~min}$. Then, the samples were washed three times with acetone at room temperature for $30 \mathrm{~min}$. The tissue samples were embedded in a solution [acetone: Optimal cutting temperature compound (Wuhan Servicebio Technology Co., Ltd.); $2: 1 ; \mathrm{v} / \mathrm{v}]$ for $4 \mathrm{~h}$ and then stored overnight at room temperature. Subsequently, the tissues were embedded in $100 \%$ embedding medium for $3 \mathrm{~h}$ at $37^{\circ} \mathrm{C}$. Next, the tissues were cured in a drying oven at $37^{\circ} \mathrm{C}$ overnight, at $45^{\circ} \mathrm{C}$ for $12 \mathrm{~h}$, and at $60^{\circ} \mathrm{C}$ for $24 \mathrm{~h}$. Finally, the tissues were cut to $50-\mathrm{nm}$ thick sections using an ultramicrotome and stained with $2 \%$ uranyl acetate and lead citrate (Wuhan Servicebio Technology Co., Ltd.) with pH 12 at room temperature for $10 \mathrm{~min}$. The ultrathin sections were then examined and imaged using a Hitachi H-7650 transmission electron microscope (TEM; Hitachi, Ltd.), with magnification $\mathrm{x} 3,500$. 
Tissue cAMP level assay. Liver tissue were collected at $6 \mathrm{~h}$ of reperfusion. A cAMP complete ELISA kit (cat. no. ab133051; Abcam) was used to determine the cAMP levels in liver tissue samples, according to the manufacturer's instructions.

Statistical analysis. SPSS 11.0 (SPSS, Inc.) was used for the statistical analysis. The data are expressed as the mean \pm standard deviation (SD). Statistical analyses were performed using unpaired two-tailed Student's t-test or one-way ANOVA followed by Tukey's post-hoc test, with $\mathrm{P}<0.05$ considered to indicate statistical significance.

\section{Results}

EP4 protein expression during hepatic I/R injury. In the present study, EP4 protein expression during rat hepatic I/R injury was examines using immunochemistry and western blot analyses. As indicated in Fig. 1, EP4 expression was downregulated in hepatocytes compared with the sham liver samples. After $2 \mathrm{~h}$ of reperfusion following $60 \mathrm{~min}$ of ischemia, the EP4 protein was prominently expressed in the membranes as well as in the cytoplasm of hepatocytes, indicating that I/R induced EP4 protein expression during early reperfusion. The expression of EP4 was lower in I/R-injured livers after $6 \mathrm{~h}$ compared with after $2 \mathrm{~h}$ of reperfusion (Fig. 1B), indicating that decreased EP4 expression may be associated with liver injury during reperfusion. Thus, in the following experiments, the effects of activated EP4 signaling on hepatic I/R injury were examined by subcutaneously injecting rats with the EP4-specific agonist CAY prior to reperfusion.

EP4 agonism protects against hepatic $I / R$ injury in a dose-dependent manner. To examine the dose-response relationship between CAY and hepatic I/R, rats received CAY three times at a dose of $0.1,0.5,1$ or $10 \mathrm{mg} / \mathrm{kg}$. Liver sections obtained from the ischemic lobe after $6 \mathrm{~h}$ of reperfusion were subjected to histopathological analysis (Fig. 2A). A semiquantitative scale was used to further determine the level of hepatocellular necrosis. The necrosis rates after $6 \mathrm{~h}$ of reperfusion following $60 \mathrm{~min}$ of ischemia for the $0.1,0.5$, 1 and $10 \mathrm{mg} / \mathrm{kg}$ treatments were $33.5 \pm 9.4,31.7 \pm 8.3,22.5 \pm 6.0$ and 20.0 \pm 5.1 , respectively (Fig. 2C). The current data indicate that this EP4 agonist inhibits hepatic I/R injury in a dose-dependent manner. Therefore, the minimal effective dose of CAY $(1 \mathrm{mg} / \mathrm{kg})$ was used to further investigate the protective mechanisms of the EP4 agonist against hepatic I/R.

EP4 agonism protects the liver during reperfusion by inhibiting MPTP opening. An MPTP opener, CATR (28), was used to determine the effect of the EP4 agonist on MPTP modulation during I/R. As indicated in Fig. 3A, I/R insult significantly induced hepatic injury by increasing serum ALT and AST levels in animals over 2 and $6 \mathrm{~h}$ of reperfusion, and treatment with $1 \mathrm{mg} / \mathrm{kg}$ CAY markedly decreased the serum ALT and AST levels in I/R animals. Next, hepatocyte necrosis and apoptosis were evaluated in each group after $6 \mathrm{~h}$ of reperfusion using H\&E and TUNEL staining. As indicated in Fig. 3B and $\mathrm{C}$, the hepatocyte necrosis rates and TUNEL index values were significantly lower in the I/R + CAY group compared with the I/R group. Notably, the protective effect produced by
CAY was partially reversed when the MPTP opener CATR was administered $30 \mathrm{~min}$ prior to I/R insult. The current results indicate that EP4 activation with CAY significantly protects the liver, and that MPTP opening may serves an important role in this effect.

To further clarify the effect of EP4 signaling on MPTP modulation during I/R, ROS levels were examined in hepatic tissues and isolated hepatocyte mitochondria, in order to determine the CRC, which is an index used to evaluate MPTP susceptibility, after 2 and 6 h of reperfusion. As shown in Fig. 4, compared with the I/R group, the I/R + CAY group exhibited significantly reduced liver ROS levels (Fig. 4A) and increased mitochondrial CRC values (Fig. 4B), indicating that MPTP opening is inhibited by EP4 activation. However, when the MPTP opener CATR was administered prior to ischemia, the protective effects induced by the EP4 agonist were significantly reversed; the ROS levels in liver tissues were significantly increased (Fig. 4A) and the CRC levels significantly reduced (Fig. 4B) in the animals treated with both CATR and CAY compared with those treated with CAY alone, over 2 and $6 \mathrm{~h}$ of reperfusion. To further confirm this result, hepatocyte ultrastructure was observed after $6 \mathrm{~h}$ of reperfusion using transmission electron microscopy. As revealed in Fig. 4C, hepatocyte nuclei remained intact in both the sham and I/R + CAY groups, with most of the mitochondrial morphology remaining intact. However, nuclear chromatin condensation was found in the I/R group, and most of the mitochondria were swollen or destroyed in both the I/R and $\mathrm{I} / \mathrm{R}+\mathrm{CAY}+\mathrm{CATR}$ groups. Given that MPTP opening serves a key role in I/R-induced cell death, the current data further confirm that the protective effect of EP4 activation on hepatic $\mathrm{I} / \mathrm{R}$ is achieved by inhibition of MPTP opening.

EP4 regulates MPTP opening via the ERK1/2-GSK3 $\beta$ pathway. To further investigate the signaling cascades of EP4-assicated MPTP modulation during I/R, the changes in cAMP levels and ERK1/2 signaling were measured in hepatocytes. As expected, EP4 activation significantly increased cAMP concentrations and subsequent ERK1/2 signaling activation by enhancing p-ERK $1 / 2$ levels in the liver tissue after $6 \mathrm{~h}$ of reperfusion (Fig. 5A and B). ERK1/2 is an intracellular signaling molecule that influences various functions (including cell metabolism and development) and interacts with a variety of intracellular signaling cascades. Within these cascades, GSK $3 \beta$ and STAT3 have been confirmed to be key molecules regulating MPTP opening $(2,6,29)$. Thus, changes in expression of GSK $3 \beta$ and JAK-STAT3 signaling proteins were evaluated in hepatocytes after $6 \mathrm{~h}$ of reperfusion. As indicated in Fig. 5C, the I/R group exhibited significantly downregulated p-GSK $3 \beta$ expression, compared with the sham group. However, compared with I/R alone, the EP4 agonist significantly increased p-GSK3 $\beta$ expression in the liver tissue, suggesting that EP4 activation may increase GSK3 $\beta$ phosphorylation during reperfusion. In addition, as revealed in Fig. 5D and E, I/R stimulated increases in JAK2 phosphorylation and subsequent STAT3 phosphorylation, compared with sham treatment. However, compared with I/R alone, the EP4 agonist failed to further stimulate the phosphorylation of JAK2 and STAT3. The current results indicate that EP4 activation-associated MPTP 
A

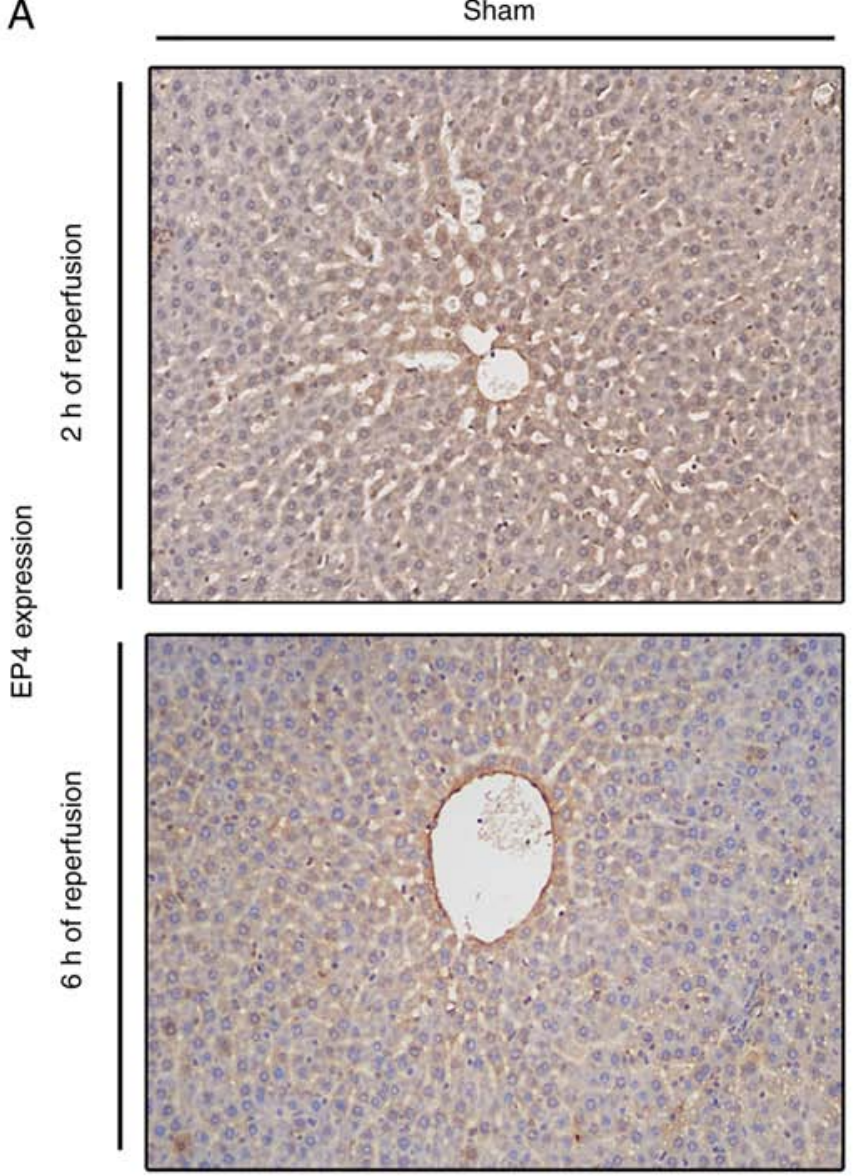

I/R
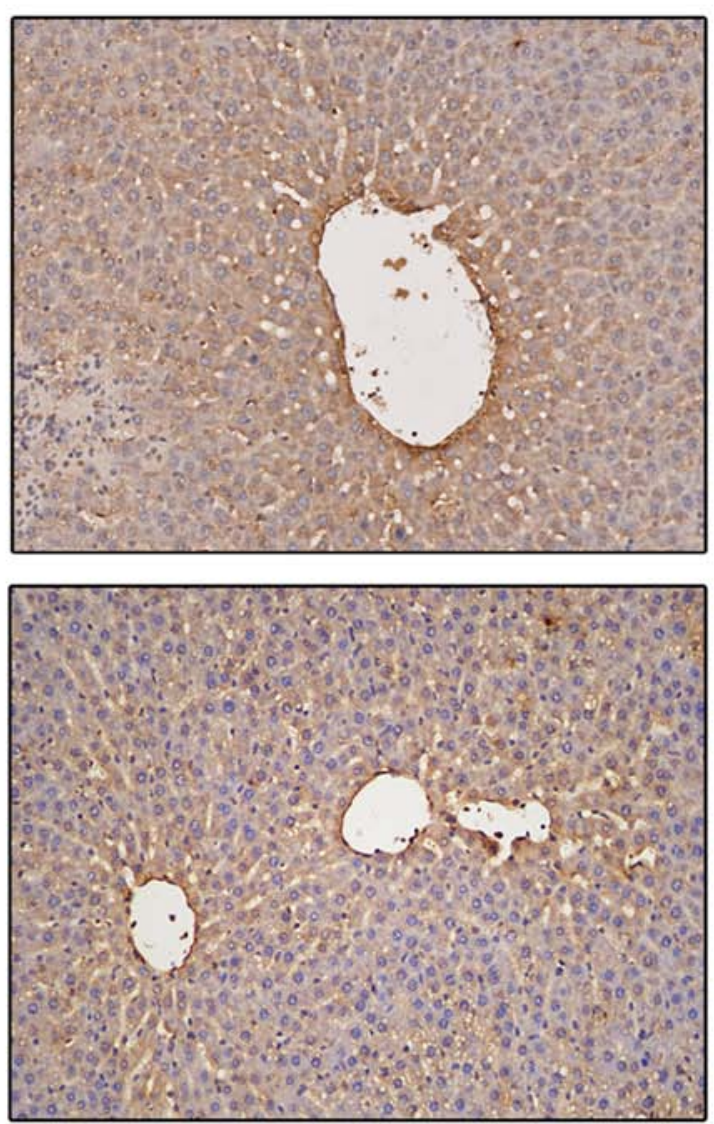

B

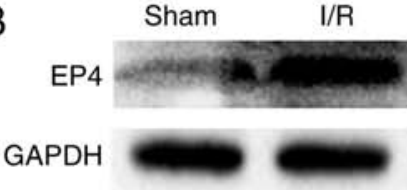

$2 \mathrm{~h}$ of reperfusion

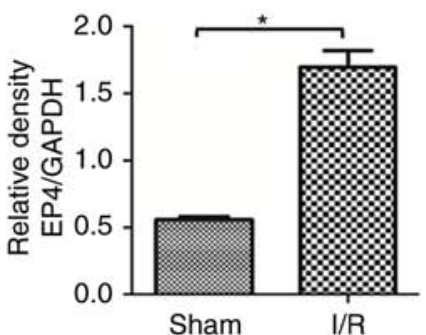

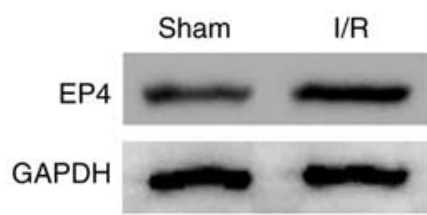

$6 \mathrm{~h}$ of reperfusion

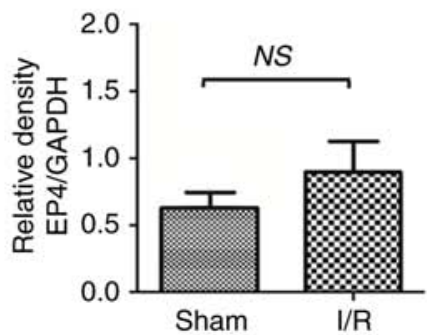

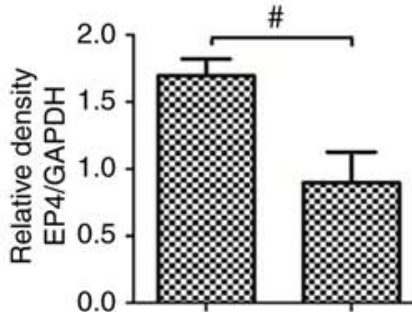

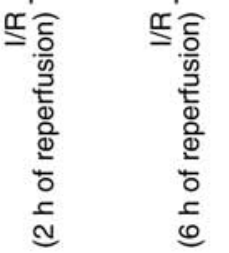

Figure 1. EP4 protein expression in the rat liver during reperfusion. (A) Immunohistochemical and (B) western blot analyses of EP4 protein expression in the rat liver after 2 and $6 \mathrm{~h}$ of reperfusion following $60 \mathrm{~min}$ of ischemia. EP4 was prominently expressed in the membranes as well as in the cytoplasm of hepatocytes and on sinusoidal cells, mainly in the periportal region (magnification, x100). Higher EP4 protein expression was found in I/R livers than in sham livers after $2 \mathrm{~h}$ of reperfusion. After $6 \mathrm{~h}$ of reperfusion, EP4 expression decreased. Differences were evaluated using the unpaired two-tailed Student's t-test; ${ }^{*} \mathrm{P}<0.05$ vs. sham-operated rats, ${ }^{\#} \mathrm{P}<0.05$ vs. $\mathrm{I} / \mathrm{R}(2 \mathrm{~h}$ of reperfusion) rats. $\mathrm{n}=6$ per group. $N S$, no significant; $\mathrm{I} / \mathrm{R}$, ischemia/reperfusion; EP4, prostaglandin $\mathrm{E}$ receptor subtype 4 .

inhibition, and subsequent hepatoprotection, may be associated with increased cAMP concentration and subsequent ERK1/2-GSK3 $\beta$ signaling activation.

Finally, to further confirm the role of ERK1/2-GSK3 $\beta$ signaling in EP4-associated MPTP modulation, PD, an ERK1/2 inhibitor, was used to block the liver protection mediated by CAY. As depicted in Fig. 6, the necrotic hepatocyte percentages and ROS levels were significantly higher in the I/R + CAY + PD group than in the I/R + CAY group (Fig. 6A and D), while the CRC level was significantly lower (Fig. 6C). Notably, p-GSK3 $\beta$ expression was inhibited in the animals pretreated with PD after $6 \mathrm{~h}$ of reperfusion (Fig. 6B). Thus, the intraperitoneal injection of the ERK1/2 inhibitor prior to ischemia significantly reversed the protective effect of CAY during hepatic I/R, further confirming that EP4 regulates the signaling cascade of MPTPs, via the ERK1/2-GSK3 $\beta$ pathway. 

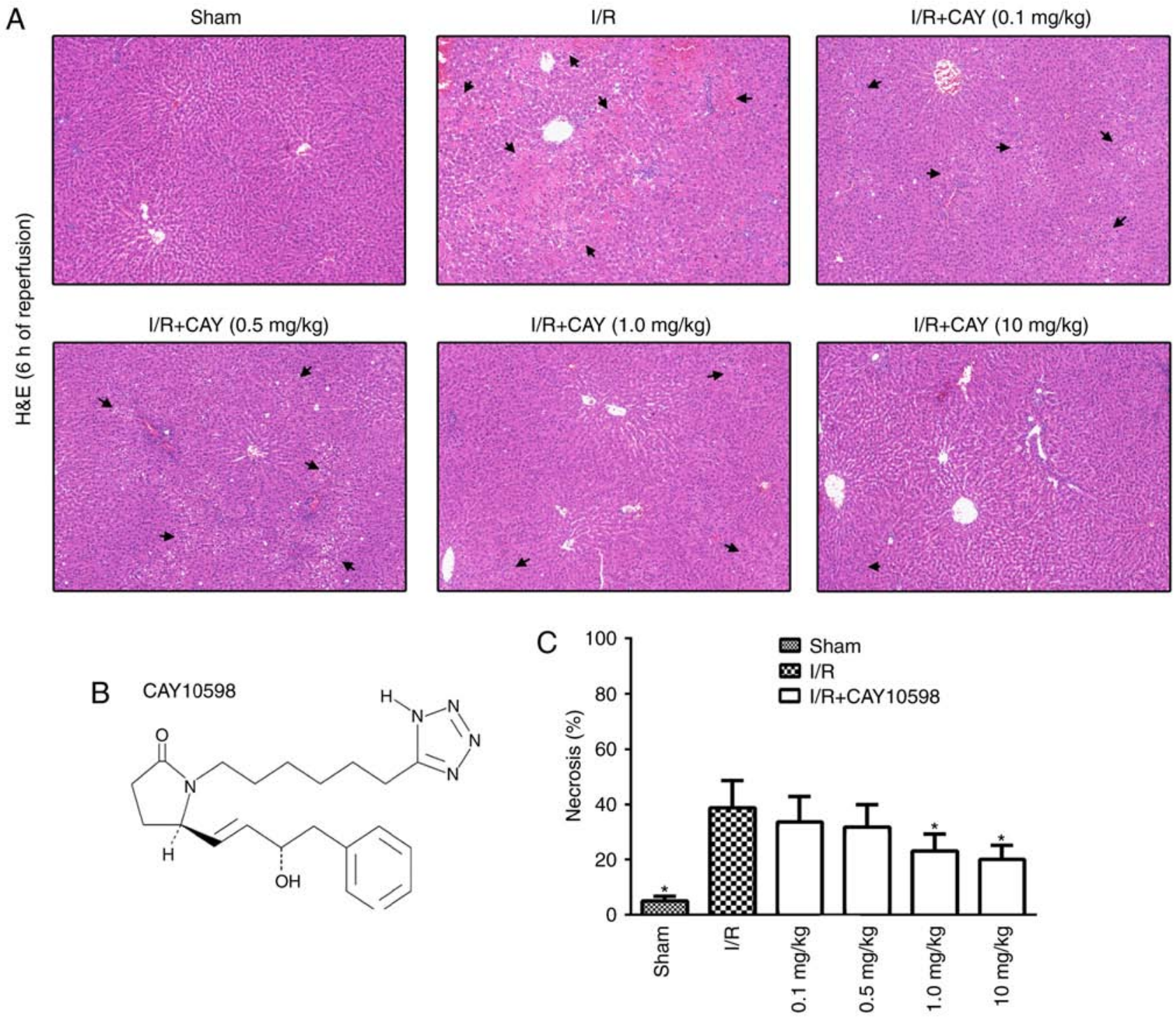

Figure 2. EP4 agonism protects liver function in a dose-dependent manner. (A) H\&E staining of livers collected after $6 \mathrm{~h}$ of reperfusion (magnification, $\mathrm{x} 100$ ). (B) Molecular structure of CAY, a highly specific EP4 receptor agonist. (C) Bar graphs indicating the percentages of necrotic cells measured in H\&E-stained liver sections from animals that received the EP4 agonist at different doses. The highest dose $(10 \mathrm{mg} / \mathrm{kg}$ at $2.5,0.5$ and $0 \mathrm{~h}$ before reperfusion) was the most effective against hepatic injury. The results indicated a dose-dependent decrease in necrosis. $n=6$. ${ }^{~} \mathrm{P}<0.05 \mathrm{vs}$. I/R. I/R, ischemia/reperfusion; EP4, prostaglandin E receptor subtype 4; H\&E, hematoxylin and eosin; CAY, CAY10598.

Taken together, the present results indicate that EP4 activation protects the liver against I/R by activating ERK1/2-GSK3 $\beta$ signaling and further inhibiting MPTP opening.

\section{Discussion}

The mechanism of $I / R$ is complex and involves extensive ROS production, inflammatory responses mediated by innate immune cells (including endothelial cells, macrophages and neutrophils) and apoptosis $(1,3,7,9,12)$. The factors that contribute to the initiation of this pathological process are a disrupted supply of oxygen to cells and a lack of ATP production (1). Mitochondria are organelles that regulate oxidative phosphorylation-mediated ATP production, and I/R injury is closely associated with the regulation of mitochondrial function $(2,30)$. It has previously been revealed that COX-2 inhibition reduces hepatic I/R injury via modulation of MPTP opening (7). The present study further investigated the regulation of mitochondrial function and the signaling cascade initiated by EP4 signaling, downstream of COX-2.

EP4 is a Gas (Gs) protein-coupled receptor that serves an important role in various pathophysiological processes by increasing the levels of the secondary messenger cAMP (12-16). There is evidence that endogenous EP4 signaling is involved in $\mathrm{I} / \mathrm{R}$ injury, as studies on I/R in the liver and brain have revealed that an EP4 agonist can reduce organ damage $(12,15)$. Consistent with a report by Kuzumoto et al (12), our preliminary study also revealed that EP4 expression was significantly upregulated in liver samples from rats and humans, following I/R. Notably, the expression level of EP4 was lower in I/R-injured livers after $6 \mathrm{~h}$ of reperfusion than after $2 \mathrm{~h}$ of reperfusion, indicating the possibility that decreased EP4 expression may be associated with liver injury during reperfusion. Indeed, alterations to intracellular signaling may be dynamic during reperfusion. A similar trend has also been reported in GSK3 $\beta$ signaling. Increased phosphorylation of GSK3 $\beta$ on Ser9 has 
A

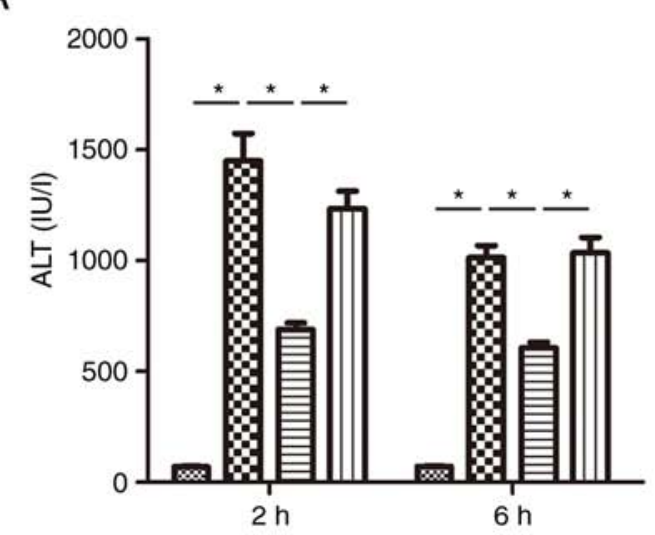

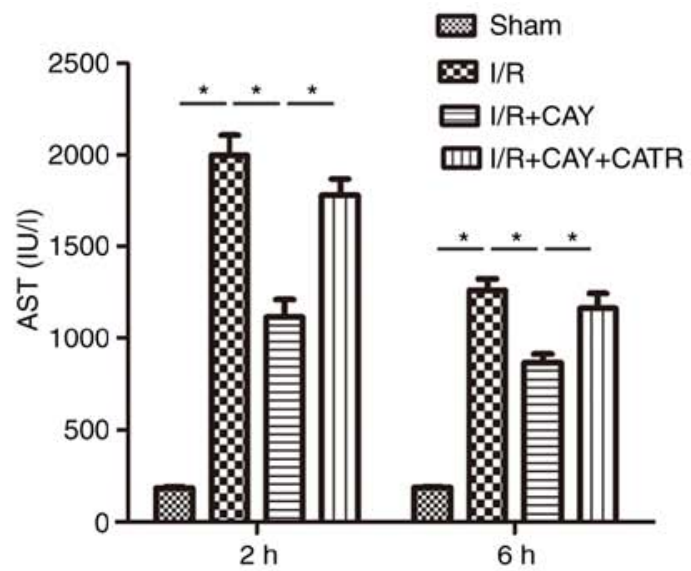

I/R

$1 / R+C A Y+C A T R$
$\mathrm{I} / \mathrm{R}+\mathrm{CAY}$

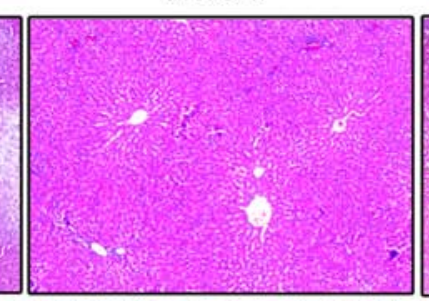

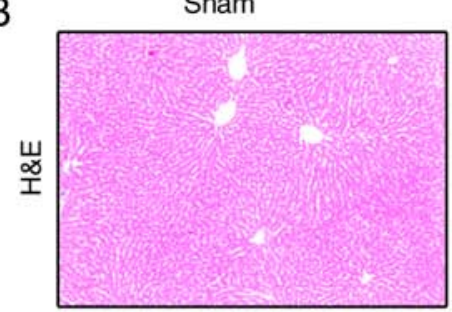
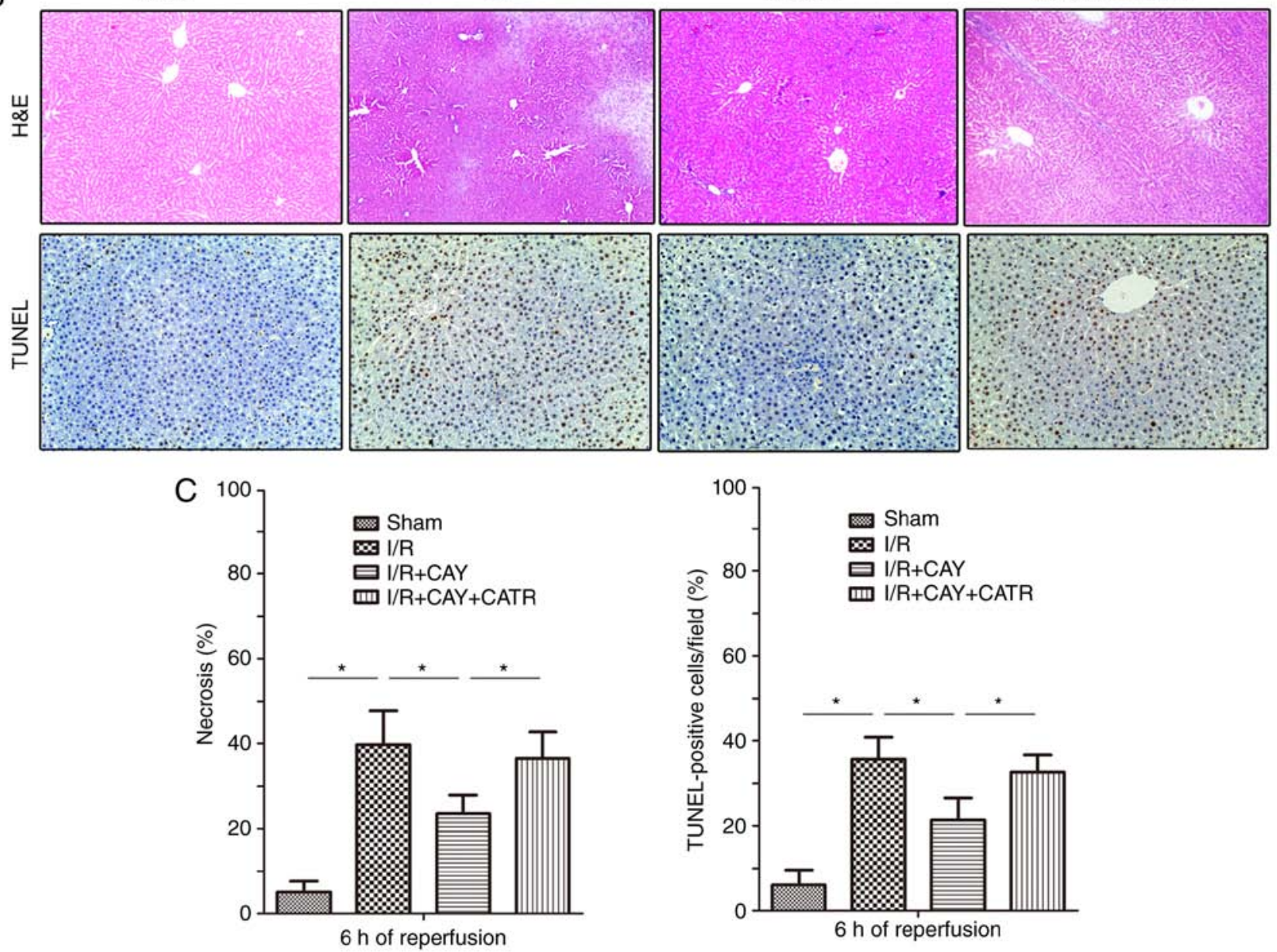

Figure 3. EP4 agonism significantly reduces liver injury during I/R. CAY ( $1 \mathrm{mg} / \mathrm{kg})$ was used to further investigate the protective effect of an EP4 agonist on hepatic I/R. (A) Serum ALT and AST levels in animals after 2 and $6 \mathrm{~h}$ of reperfusion. (B) H\&E staining and TUNEL staining of liver tissue collected after $6 \mathrm{~h}$ of reperfusion; 100x magnification. In the sham group, the morphology of the liver was regular, and intact hepatocytes were observed. In contrast, large numbers of necrotic hepatocytes and disordered hepatic sinusoidal morphology were visible in the I/R groups. Only local hepatocyte necrosis was found in the I/R+CAY treatment group. (C) Percentages of necrotic cells measured in H\&E-stained sections and percentages of apoptotic cells measured in TUNEL-stained sections. $\mathrm{n}=6$. $^{*} \mathrm{P}<0.05$. I/R, ischemia/reperfusion; EP4, prostaglandin E receptor subtype 4; H\&E, hematoxylin and eosin; TUNEL, terminal deoxynucleotidyl transferase-mediated dUTP nick-end labeling; CAY, CAY10598; ALT, alanine aminotransferase; AST, aspartate aminotransferase; CATR, carboxyatractyloside.

been demonstrated to reduce I/R damage in numerous organs, especially in the liver and heart $(2,4,6,29,31)$. However, during early reperfusion, increased p-GSK3 $\beta$ expression was reported in myocardial I/R tissue, when physical and pharmacological increases in $\mathrm{p}$-GSK3 $\beta$ expression conferred a protective effect during I/R $(32,33)$.
Mitochondria are organelles that rely on cellular oxygen uptake and are the core utilizers of cellular oxygen. PGE2 regulates the oxygen uptake of hepatocytes by interfering with the intracellular cAMP-dependent protein kinase pathway (34), it is also possible that EP4 signaling regulates mitochondrial function during hepatic I/R. Thus, the effect 


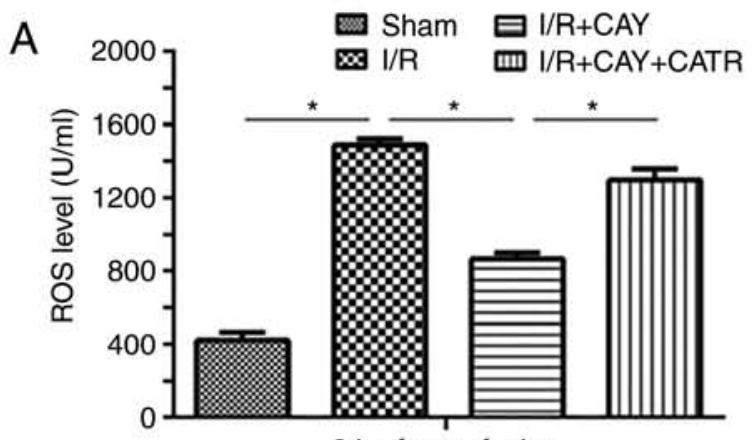

$2 \mathrm{~h}$ of reperfusion

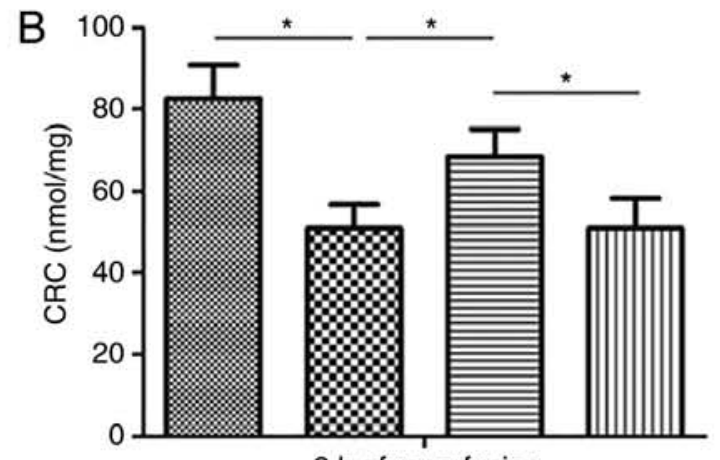

$2 \mathrm{~h}$ of reperfusion
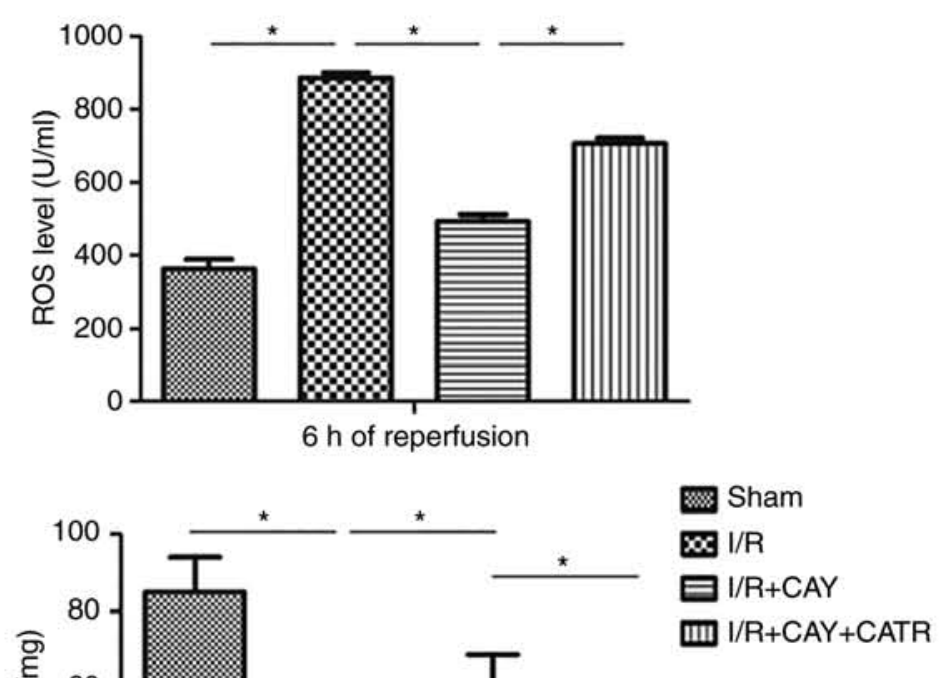

C

Sham
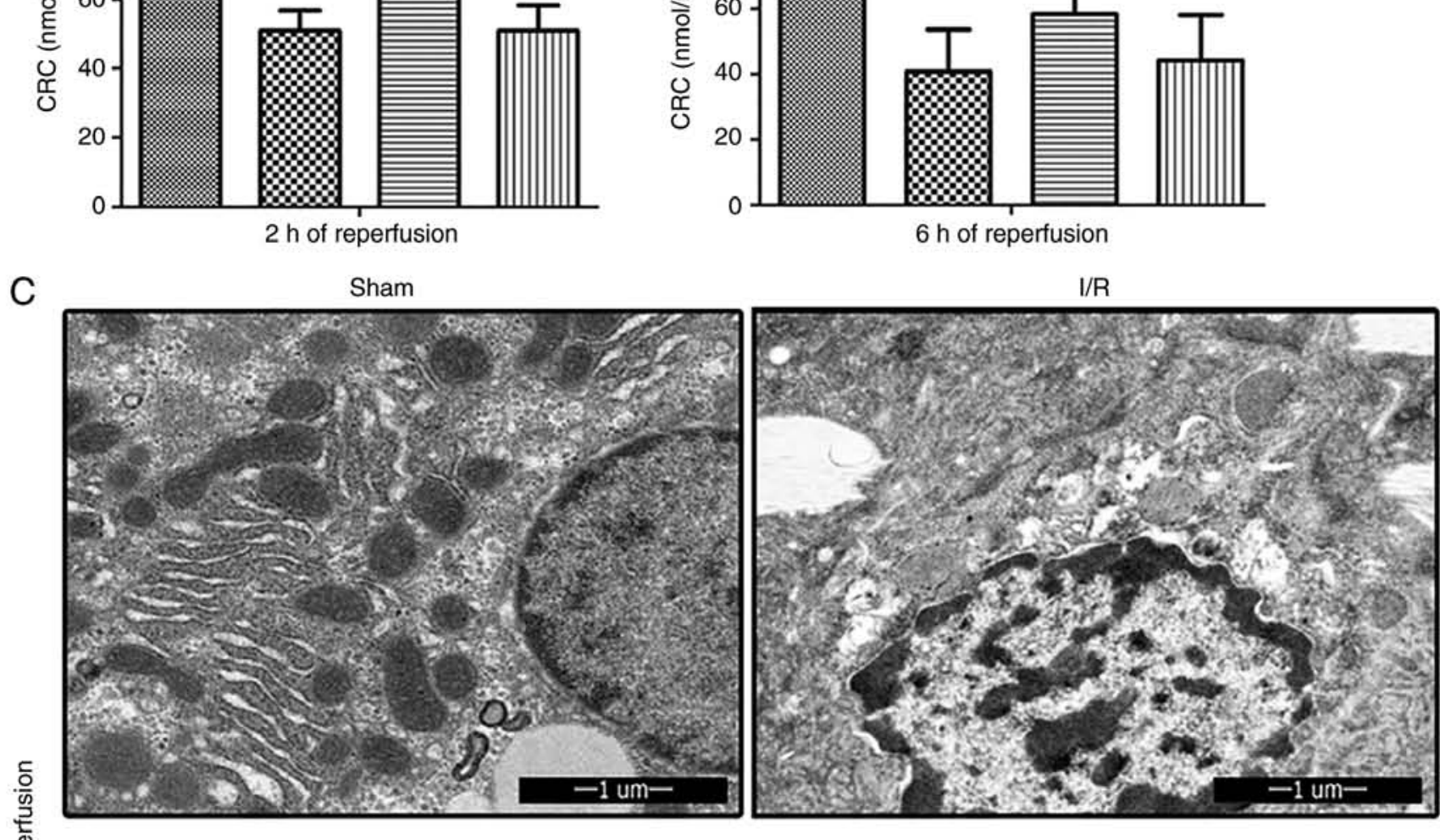

$6 \mathrm{~h}$ of reperfusion
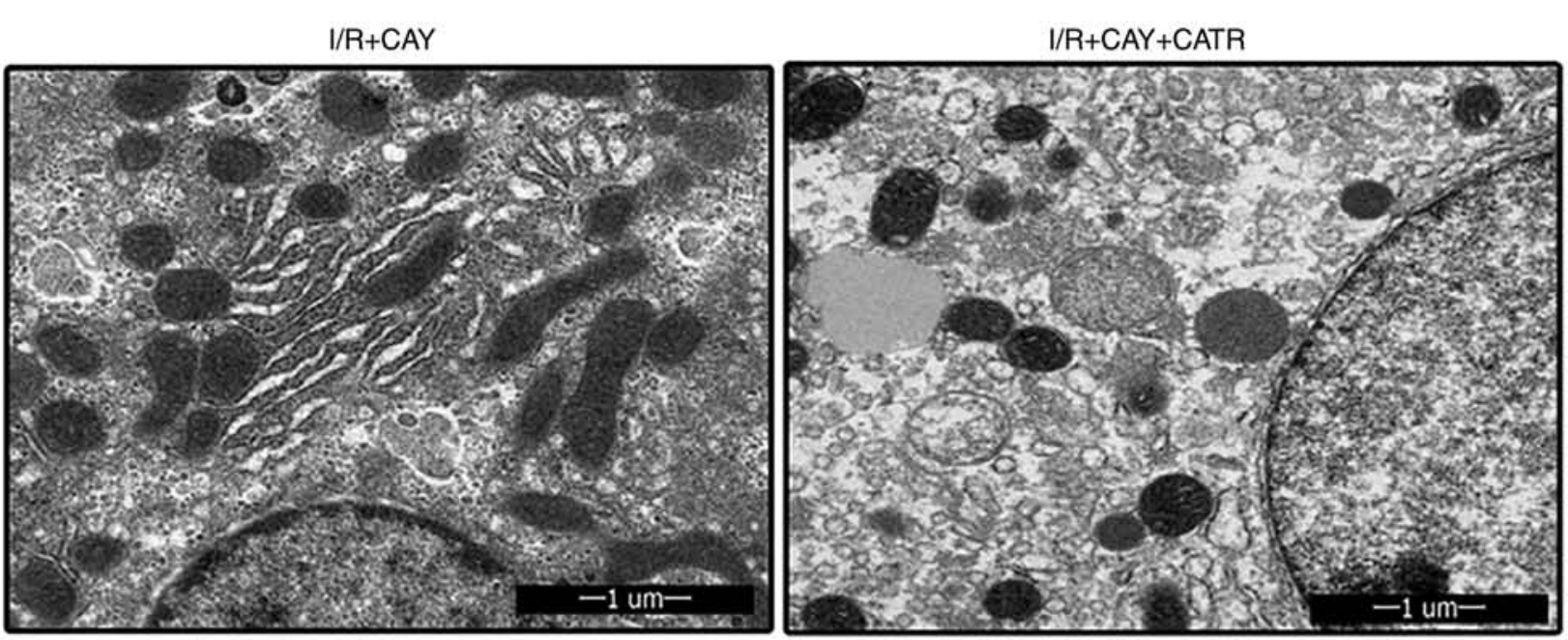

Figure 4. EP4 agonism protects mitochondria by reducing tissue ROS levels and increasing mitochondrial CRC during reperfusion. (A) ROS levels in liver tissue after 2 and $6 \mathrm{~h}$ of reperfusion. (B) CRC levels in liver mitochondria after 2 and $6 \mathrm{~h}$ of reperfusion. (C) Ultrastructure of hepatocytes in liver tissue samples observed by transmission electron microscopy after $6 \mathrm{~h}$ of reperfusion. $\mathrm{n}=6$. " $\mathrm{P}<0.05$. I/R, ischemia/reperfusion; EP4, prostaglandin E receptor subtype 4; CAY, CAY10598; CATR, carboxyatractyloside; CRC, calcium retention capacity; ROS, reactive oxygen species. 


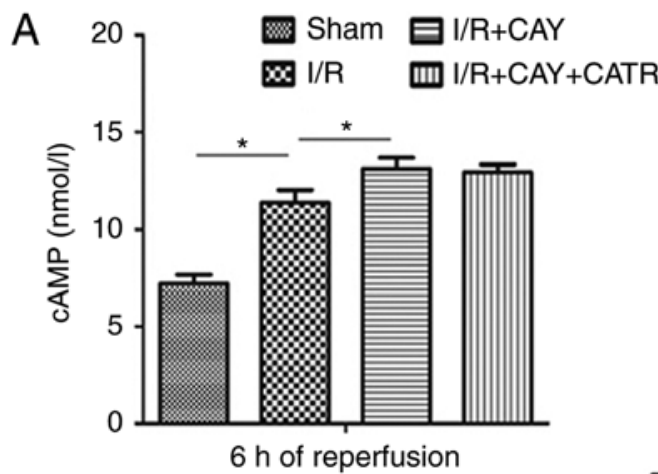

B

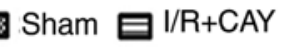

$\otimes \mathrm{l} / \mathrm{R} \quad \mathrm{m} \mathrm{I} / \mathrm{R}+\mathrm{CAY}+\mathrm{CATR}$
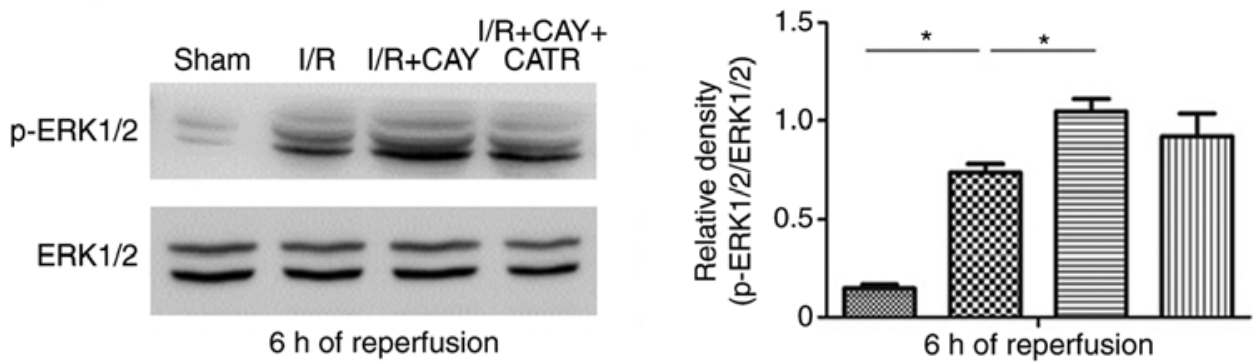

C

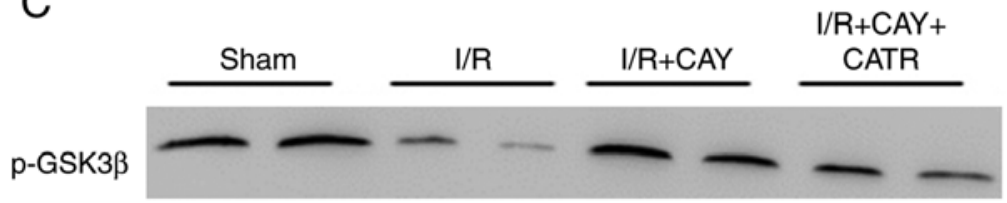

GSK3B

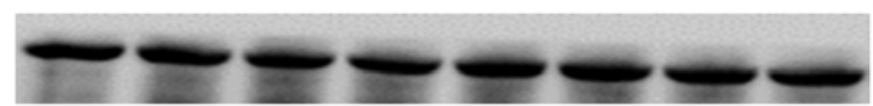

$6 \mathrm{~h}$ of reperfusion
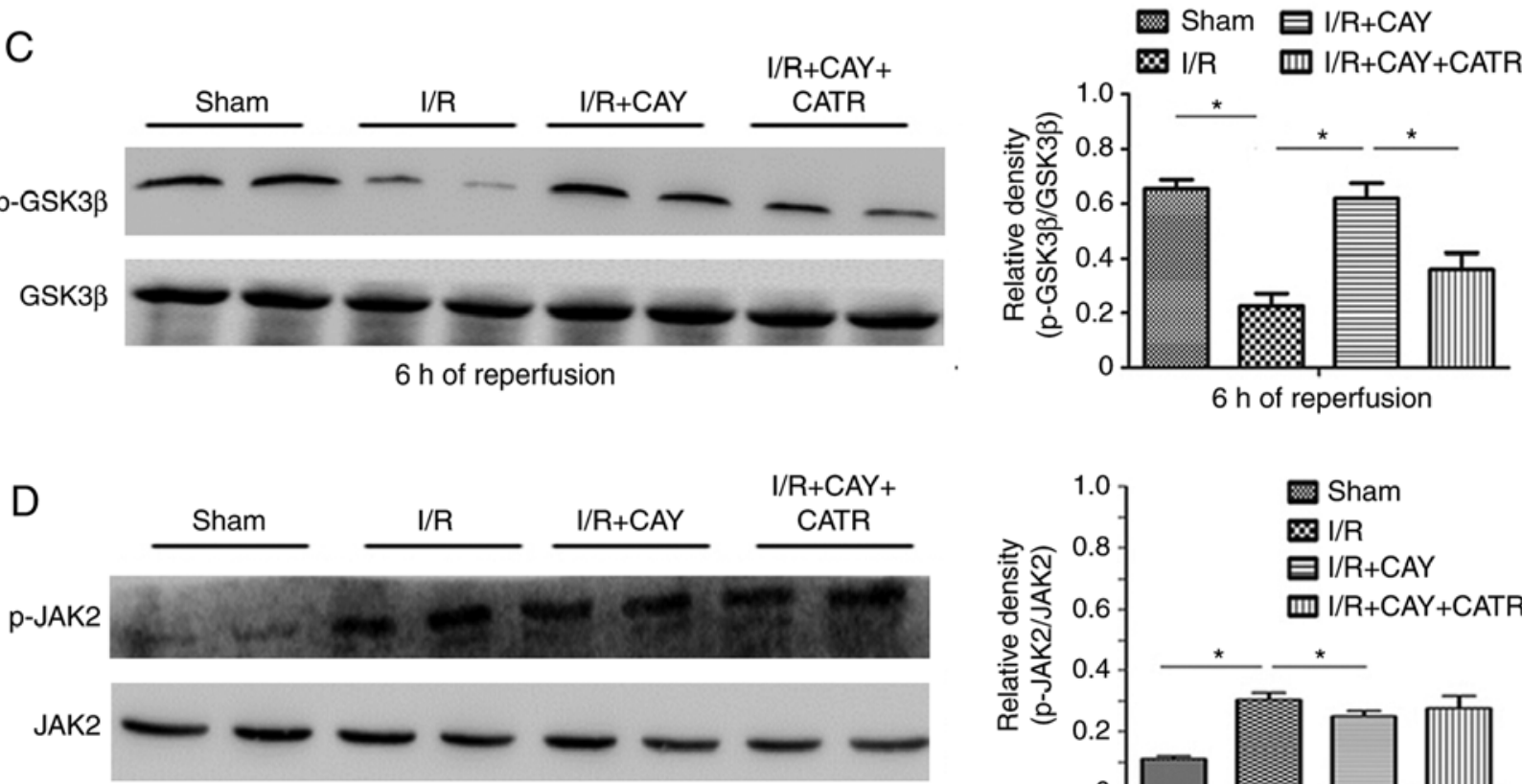

$6 \mathrm{~h}$ of reperfusion

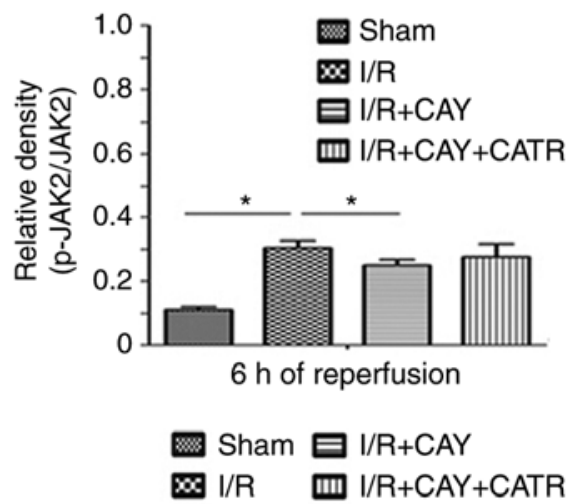

E
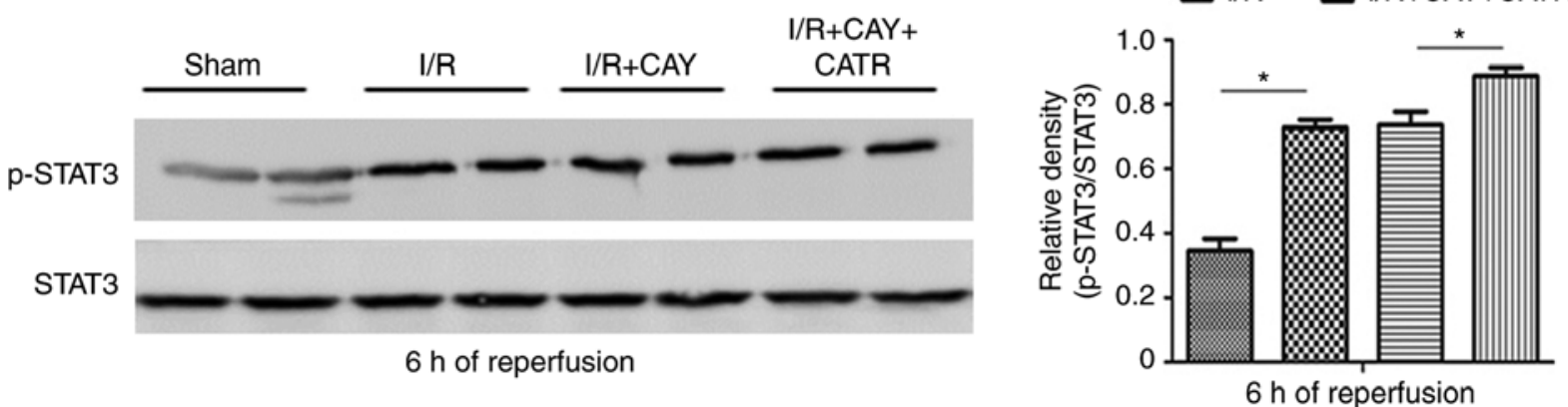

Figure 5. Effects of an EP4 agonist on cAMP-ERK1/2-GSK3 $\beta$ and JAK2-STAT3 signaling after $6 \mathrm{~h}$ of reperfusion. (A) cAMP levels in liver tissues. Western blot analysis was performed to determine the protein expression of (B) p-ERK1/2 and ERK1/2, (C) p-GSK3 $\beta$ and GSK3 $\beta$, (D) p-JAK2 and JAK2 and (E) p-STAT3 and STAT3 in liver tissues. $n=6$. ${ }^{*} \mathrm{P}<0.05$. I/R, ischemia/reperfusion; EP4, prostaglandin E receptor subtype 4; CAY, CAY10598; CATR, carboxyatractyloside; p-, phosphorylated; JAK, janus kinase; STAT, signal transducer and activator of transcription; GSK3 $\beta$, glycogen synthase kinase $3 \beta$. 
A
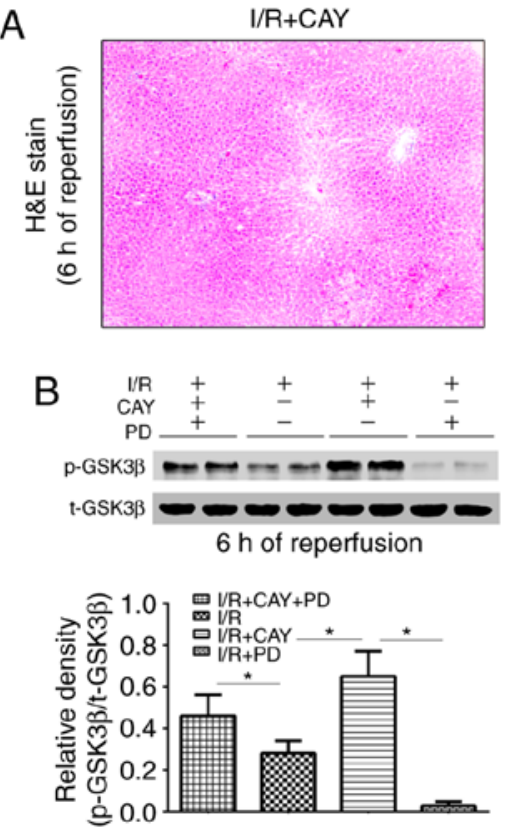

$\mathrm{I} / \mathrm{R}+\mathrm{CAY}+\mathrm{PD}$
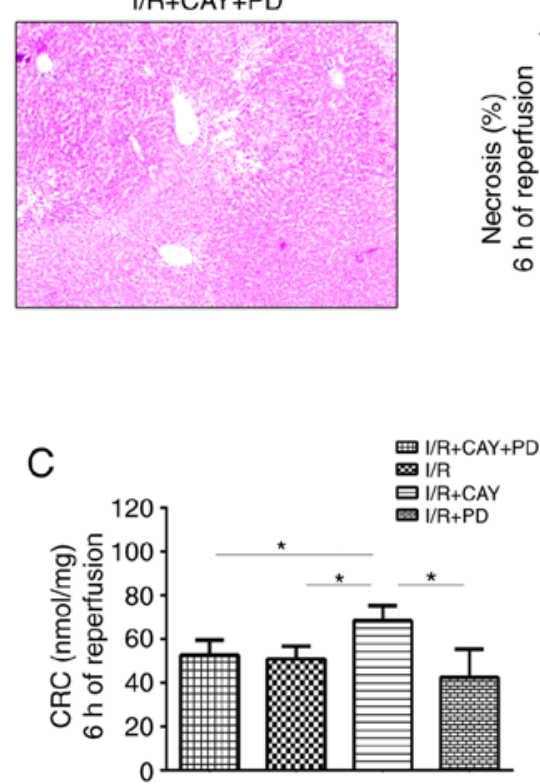
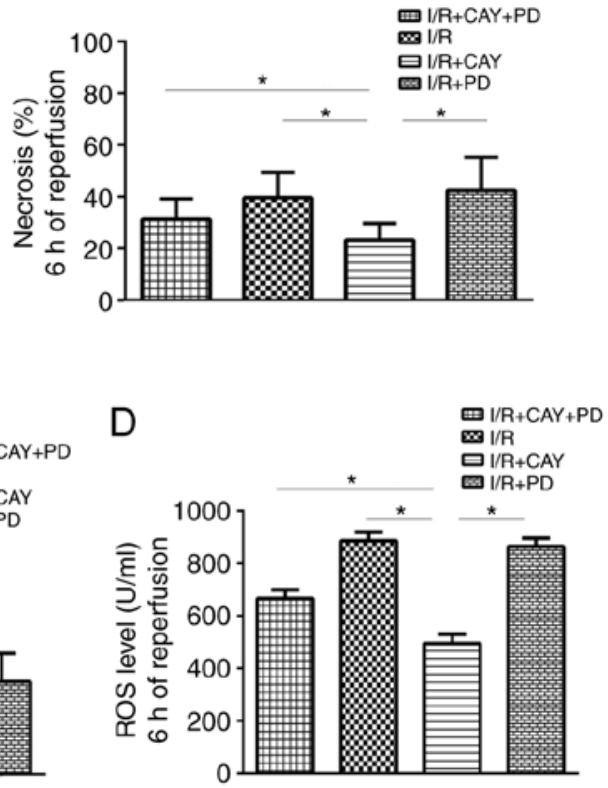

Figure 6. ERK1/2 inhibition decreases EP4 agonist-mediated hepatoprotection after 6 h of reperfusion. (A) H\&E staining of liver tissues (magnification, x100) and percentages of necrotic cells measured in the H\&E-stained sections. (B) Western blot analysis of p-GSK3 $\beta$ and GSK3 $\beta$ protein expression in liver tissues. (C) CRC levels in liver mitochondria. (D) ROS levels in liver tissues. $\mathrm{n}=6$. "P<0.05. I/R, ischemia/reperfusion; EP4, prostaglandin E receptor subtype 4; H\&E, hematoxylin and eosin; CAY, CAY10598; PD, PD98059; CATR, carboxyatractyloside; ROS, reactive oxygen species; CRC, calcium retention capacity; GSK3 $\beta$, glycogen synthase kinase $3 \beta$.

of EP4 on hepatic I/R and the mechanism underlying the EP4 signaling-associate modulation of MPTPs were investigated in the present study.

In an animal model of $70 \%$ partial liver I/R, CAY (an EP4 agonist) was used to observe the effect of EP4 activation on MPTP opening and liver damage. CAY is a very potent EP4 agonist and is highly selective of EP4 over EP1-3 or other prostanoid receptors (35). Studies have indicated that CAY effectively activates endogenous EP4 signaling by increasing cAMP production in various animal and human tissues (36-40). In the present study, CAY protected the liver from $\mathrm{I} / \mathrm{R}$ in a dose-dependent manner. Subcutaneous injection of CAY at a dose of $1 \mathrm{mg} / \mathrm{kg}$ significantly reduced serum ALT and AST levels, and necrotic and apoptotic cell percentages, during reperfusion. Furthermore, the EP4 agonist significantly reduced liver ROS levels, increased mitochondrial CRC values and protected mitochondrial morphology. CATR is an MPTP opener and has been demonstrated to protect MPTP opening by stabilizing ADP/ATP translocase on the cytosolic side of the mitochondrial inner membrane (28). In the current study, CATR also partially reversed the protective effects of the EP4 agonist on the liver and mitochondria, further confirming the key role of EP4 signaling in MPTP modulation during hepatic I/R.

MPTPs are functional channels located on the inner mitochondrial membrane that are usually closed. However, under specific circumstances, such as hypoxia or I/R, a large number of free radicals promote MPTP opening, further causing mitochondrial damage and proapoptotic factor release (2). Numerous studies have confirmed that the mitochondrial dysfunction caused by MPTP opening serves an important role in cell necrosis and apoptosis during I/R $(2,7,30,41)$. In the early reperfusion stage, I/R damage can be directly ameliorated if MPTP opening is effectively inhibited (4,30).
MPTP susceptibility is affected by many factors. GSK3 $\beta$ and STAT3 have been demonstrated to be important regulators of MPTP opening, as increased phosphorylation of GSK3 $\beta$ and STAT3 inhibits MPTP opening $(2,6,29,42,43)$. GSK3 $\beta$, a highly conserved serine/threonine protein kinase, is ubiquitously expressed and active in quiescent cells; however, both the Wnt and PI3K/protein kinase B (Akt) signaling pathways downregulate its activity via inhibitory phosphorylation of serine residues $(5,42)$. Several previous studies have confirmed that protection against $\mathrm{I} / \mathrm{R}$ injury is enhanced via Akt-GSK3 $\beta$ signaling activation $(32,44,45)$. A classic protective strategy, ischemia preconditioning (IPC), is considered to trigger multiple protective signaling pathways during $\mathrm{I} / \mathrm{R}$, including the PKA, PI3K/Akt, PKC and ERK1/2 pathways, of which GSK3 $\beta$ is a crucial downstream regulator $(23,46,47)$. It has previously been revealed that enhanced phosphorylation of GSK3 $\beta$ on Ser9 in rats with liver I/R inhibits MPTP opening and reduces liver damage $(4,31)$. Varela et al $(48)$ also reported that a GSK3 $\beta$ inhibitor (indirubin-3'-oxime) prevents hepatic I/R damage by inhibiting MPTP opening. Phosphorylated GSK3 $\beta$ inhibits MPTP opening via multiple mechanisms, including preservation of hexokinase II in the MPTP complex, prevention of the interaction of cyclophilin-D with adenine nucleotide translocase, inhibition of p53 activation and attenuation of ATP hydrolysis during ischemia (42). In the present study, it was revealed that an EP4 agonist also significantly increased p-GSK3 $\beta$ expression in liver tissue during reperfusion, indicating that EP4 modulates MPTP opening via GSK3 $\beta$. GSK3 $\beta$ is a convergence point for multiple cell signaling cascades (49), such as the classic reperfusion injury salvage kinase (RISK) pathway and the survivor activating factor enhancement (SAFE) pathway (4-6), justifying the choice of this signal transducer as a target for potentiating pro-survival cascades and maximizing organ protection $(50,51)$. 
The RISK pathway consists of Akt-GSK3 $\beta$ and ERK1/2 signaling events, whereas the SAFE pathway involves the activation of tumor necrosis factor (TNF)- $\alpha$ and the JAK-STAT axis (52). Thus, pharmacological EP4 activation may directly or indirectly affect one or more of these signals.

EP4 is described as a Gs protein-coupled receptor that induces intracellular cAMP production, resulting in PI3K-ERK1/2 signaling activation (14). The ERK1/2 signaling cascade was previously revealed to influence EP4-mediated cardiac hypertrophy (16). Wang et al (53) found that remote ischemic preconditioning (RIPC) protects the rat's liver from I/R injury by inducing the heme oxygenase-1/ERK1/2-dependent autophagy. In addition, Yang et al (54) revealed that triiodothyronine preconditioning protects against liver $\mathrm{I} / \mathrm{R}$ injury in mice by regulating autophagy through the MEK/ERK axis. Similar to the present findings, increased p-ERK1/2 expression was also found in I/R livers both in vivo and in vitro in these two experiments, indicating that ERK1/2 signaling may mediate I/R-induced liver damage $(53,54)$. Furthermore, pharmacological or physical activation of ERK1/2 signaling via further enhancement of $\mathrm{p}$-ERK1/2 levels has been shown to exert protective effects during I/R (46,53-55). In the current study, CAY treatment significantly increased cAMP concentrations and subsequent ERK1/2 signaling activation by enhancing p-ERK $1 / 2$ levels in liver tissue after $6 \mathrm{~h}$ of reperfusion, whereas the ERK1/2 signaling inhibitor PD significantly inhibited the EP4-mediated GSK3 $\beta$ phosphorylation and hepatoprotective effects, further confirming that activation of ERK1/2 signaling may alleviate I/R-induced liver damage and mediate the protective effect of CAY.

Previous studies have confirmed the role of the JAK-STAT pathway in myocardial injury $(29,43)$. For example, Gross et al (51) found that the JAK/STAT/GSK3 $\beta$ pathway is essential for opioid-induced cardioprotection. Boengler et al (6) reported that STAT3 may exert cardioprotective effects by stimulating respiration and inhibiting MPTP opening. In the current study, the use of an EP4 agonist did not significantly increase the expression of p-JAK2 and p-STAT3 during reperfusion in the context of liver $\mathrm{I} / \mathrm{R}$, which does not support the conclusion that EP4 regulates MPTPs and liver function via JAK2-STAT3 signaling.

In conclusion, the current data reveal a novel function of active EP4; the induction of ERK1/2-GSK3 $\beta$ signaling and subsequent effects of MPTP inhibition and hepatoprotection. However, considering the diversity and functional complexity of prostaglandin receptors and the complicated process of I/R-induced hepatocyte death, the present study only considered the relevant major mechanistic pathways. Nevertheless, these findings may shed new light on the clinical use of EP4 agonists for liver protection in surgical settings.

\section{Acknowledgements}

Not applicable.

\section{Funding}

The present study was partially supported by grants from the National Natural Science Foundation of China (grant nos. 81670564, 81300344, 81671304 and 81873945). The funders did not play any role in the study design, data collection and analysis, decisions regarding data release or manuscript preparation.

\section{Availability of data and materials}

The datasets used during the current study are available from the corresponding author on reasonable request.

\section{Authors' contributions}

LLC, HTX and QLW wrote the manuscript, designed the experiment, and contributed equally to this work. YQZ, WC, DYZ, FL and YHL helped conduct the experiment and data analyses; and HLF, YHL and HBY conducted the experiments and assisted with paper writing. All authors read and approved the final manuscript.

\section{Ethics approval and consent to participate}

All experiments were approved by the Changzheng Hospital Ethics Committee [approval number, CZEC (2015)-01] and were performed in compliance with the Guide for the Care and Use of Laboratory Animals published by the US National Institutes of Health (NIH publication no. 85-23, revised 1996).

\section{Patient consent for publication}

Not applicable.

\section{Competing interests}

The authors declare that they have no competing interests.

\section{References}

1. Howard TK, Klintmalm GB, Cofer JB, Husberg BS, Goldstein RM and Gonwa TA: The influence of preservation injury on rejection in the hepatic transplant recipient. Transplantation 49: 103-107, 1990.

2. Halestrap AP: What is the mitochondrial permeability transition pore? J Mol Cell Cardiol 46: 821-831, 2009.

3. Zhu J, Rebecchi MJ, Glass PS, Brink PR and Liu L: Cardioprotection of the aged rat heart by GSK-3beta inhibitor is attenuated: Age-related changes in mitochondrial permeability transition pore modulation. Am J Physiol Heart Circ Physiol 300: H922-H930, 2011.

4. Fu H, Xu H, Chen H, Li Y, Li W, Zhu Q, Zhang Q, Yuan H, Liu F, Wang Q, et al: Inhibition of glycogen synthase kinase 3 ameliorates liver ischemia/reperfusion injury via an energy-dependent mitochondrial mechanism. J Hepatol 61: 816-824, 2014.

5. Gomez L, Paillard M, Thibault H, Derumeaux G and Ovize M: Inhibition of GSK3beta by postconditioning is required to prevent opening of the mitochondrial permeability transition pore during reperfusion. Circulation 117: 2761-2768, 2008.

6. Boengler K, Hilfiker-Kleiner D, Heusch G and Schulz R: Inhibition of permeability transition pore opening by mitochondrial STAT3 and its role in myocardial ischemia/reperfusion. Basic Res Cardiol 105: 771-785, 2010.

7. Fu H, Chen H, Wang C, Xu H, Liu F, Guo M, Wang Q and Shi X: Flurbiprofen, a cyclooxygenase inhibitor, protects mice from hepatic ischemia/reperfusion injury by inhibiting GSK-3 $\beta$ signaling and mitochondrial permeability transition. Mol Med 18: 1128-1135, 2012.

8. Kwak HJ, Park KM, Choi HE, Lim HJ, Park JH and Park HY: The cardioprotective effects of zileuton, a 5-lipoxygenase inhibitor, are mediated by COX-2 via activation of PKC delta. Cell Signal 22: 80-87, 2010 
9. Hwang HS, Yang KJ, Park KC, Choi HS, Kim SH, Hong SY, Jeon BH, Chang YK, Park CW, Kim SY, et al: Pretreatment with paricalcitol attenuates inflammation in ischemia-reperfusion injury via the up-regulation of cyclooxygenase- 2 and prostaglandin E2. Nephrol Dial Transplant 28: 1156-1166, 2013

10. Ho ATV, Palla AR, Blake MR, Yucel ND, Wang YX, Magnusson KEG, Holbrook CA, Kraft PE, Delp SL and Blau HM: Prostaglandin E2 is essential for efficacious skeletal muscle stem-cell function, augmenting regeneration and strength. Proc Natl Acad Sci USA 114: 6675-6684, 2017.

11. Narumiya S and FitzGerald GA: Genetic and pharmacological analysis of prostanoid receptor function. J Clin Invest 108: 25-30, 2001.

12. Kuzumoto Y, Sho M, Ikeda N, Hamada K, Mizuno T, Akashi S, Tsurui Y, Kashizuka H, Nomi T, Kubo A, et al: Significance and therapeutic potential of prostaglandin E2 receptor in hepatic ischemia/reperfusion injury in mice. Hepatology 42: 608-617, 2005.

13. Nataraj C, Thomas DW, Tilley SL, Nguyen MT, Mannon R, Koller BH and Coffman TM: Receptors for prostaglandin E(2) that regulate cellular immune responses in the mouse. J Clin Invest 108: 1229-1235, 2001.

14. Konya V, Marsche G, Schuligoi R and Heinemann A: E-type prostanoid receptor 4 (EP4) in disease and therapy. Pharmacol Ther 138: 485-502, 2013

15. Liang X, Lin L, Woodling NS, Wang Q, Anacker C, Pan T, Merchant M and Andreasson K: Signaling via the prostaglandinE(2) receptor EP4 exerts neuronal and vascular protection in a mouse model of cerebral ischemia. J Clin Invest 121: 4362-4371, 2011.

16. Pang L, Cai Y, Tang EH, Irwin MG, Ma $\mathrm{H}$ and Xia Z: Prostaglandin $\mathrm{E}$ receptor subtype 4 signaling in the heart: Role in ischemia/reperfusion injury and cardiac hypertrophy. J Diabetes Res 2016: 1324347, 2016.

17. Mo C, Zhao R, Vallejo J, Igwe O, Bonewald L, Wetmore L and Brotto M: Prostaglandin E2 promotes proliferation of skeletal muscle myoblasts via EP4 receptor activation. Cell Cycle 14: $1507-1516,2015$

18. Naribayashi-Inomoto $\mathrm{Y}$, Ding $\mathrm{M}$, Nakata $\mathrm{H}$, Narumiya $\mathrm{S}$, Sugimoto Y, Honda A, Ichikawa A, Chiba T and Kinoshita Y: Copresence of prostaglandin EP2 and EP3 receptors on gastric enterochromaffin-like cell carcinoid in African rodents. Gastroenterology 109: 341-347, 1995.

19. Nishizawa N, Ito Y, Eshima K, Ohkubo H, Kojo K, Inoue T, Raouf J, Jakobsson PJ, Uematsu S, Akira S, et al: Inhibition of microsomal prostaglandin E synthase-1 facilitates liver repair after hepatic injury in mice. J Hepatol 69: 110-120, 2018.

20. Nakamura K, Kageyama S, Ito T, Hirao H, Kadono K, Aziz A, Dery KJ, Everly MJ, Taura K, Uemoto S, et al: Antibiotic pretreatment alleviates liver transplant damage in mice and humans. J Clin Invest 129: 3420-3434, 2019.

21. Selzner N, Selzner M, Jochum W and Clavien PA: Ischemic preconditioning protects the steatotic mouse liver against reperfusion injury: An ATP dependent mechanism. J Hepatol 39: 55-61, 2003.

22. Liu A, Dirsch O, Fang H, Dong W, Jin H, Huang H, Sun J and Dahmen U: HMGB1 translocation and expression is caused by warm ischemia reperfusion injury, but not by partial hepatectomy in rats. Exp Mol Pathol 91: 502-508, 2011.

23. Yamada F, Saito T, Abe T, Tsuchiya T, Sato Y, Kenjo A, Kimura T and Gotoh M: Ischemic preconditioning enhances regenerative capacity of hepatocytes in long-term ischemically damaged rat livers. J Gastroenterol Hepatol 22: 1971-1977, 2007.

24. Limani P, Linecker M, Oberkofler CE, Barmettler G, Kaech A, Graf R, Humar B and Clavien PA: Remote ischemic preconditioning: A novel strategy in rescuing older livers from ischemia-reperfusion injury in a rodent model. Ann Surg 264: 797-803, 2016

25. Yamamoto M, Morita T, Ishikawa $M$ and Sakamoto A: Specific microRNAs are involved in the renoprotective effects of sevoflurane preconditioning and ischemic preconditioning against ischemia reperfusion injury in rats. Int J Mol Med 45: 1141-1149, 2020.

26. Parks RJ, Murphy E and Liu JC: Mitochondrial permeability transition pore and calcium handling. Methods Mol Biol 1782 187-196, 2018

27. Ichas F,Jouaville LS, Sidash SS, Mazat JP and Holmuhamedov EL: Mitochondrial calcium spiking: A transduction mechanism based on calcium-induced permeability transition involved in cell calcium signalling. FEBS Lett 348: 211-215, 1994.
28. Novgorodov SA, Gudz TI, Kushnareva YE, Zorov DB and Kudrjashov YB: Effect of ADP/ATP antiporter conformational state on the suppression of the nonspecific permeability of the inner mitochondrial membrane by cyclosporine A. FEBS Lett 277: 123-126, 1990.

29. Barry SP, Townsend PA, Latchman DS and Stephanou A: Role of the JAK-STAT pathway in myocardial injury. Trends Mol Med 13: 82-89, 2007.

30. Juhaszova M, Zorov DB, Kim SH, Pepe S, Fu Q, Fishbein KW, Ziman BD, Wang S, Ytrehus K, Antos CL, et al: Glycogen synthase kinase-3beta mediates convergence of protection signaling to inhibit the mitochondrial permeability transition pore. J Clin Invest 113: 1535-1549, 2004.

31. Cai L, Li Y, Zhang Q, Sun H, Yan X, Hua T, Zhu Q, Xu H and $\mathrm{Fu} \mathrm{H}$ : Salidroside protects rat liver against ischemia/reperfusion injury by regulating the GSK-3 $\beta / \mathrm{Nrf} 2$-dependent antioxidant response and mitochondrial permeability transition. Eur J Pharmacol 806: 32-42, 2017.

32. Song JQ, Teng X, Cai Y, Tang CS and Qi YF: Activation of Akt/GSK-3beta signaling pathway is involved in intermedin(1-53) protection against myocardial apoptosis induced by ischemia/reperfusion. Apoptosis 14: 1061-1069, 2009.

33. Nishino Y, Webb IG, Davidson SM, Ahmed AI, Clark JE, Jacquet S, Shah AM, Miura T, Yellon DM, Avkiran M and Marber MS: Glycogen synthase kinase-3 inactivation is not required for ischemic preconditioning or postconditioning in the mouse. Circ Res 103: 307-314, 2008.

34. Qu W, Graves LM and Thurman RG: PGE(2) stimulates $\mathrm{O}(2)$ uptake in hepatic parenchymal cells: Involvement of the cAMP-dependent protein kinase. Am J Physiol 277: G1048-G1054, 1999.

35. Billot X, Chateauneuf A, Chauret N, Denis D, Greig G, Mathieu MC, Metters KM, Slipetz DM and Young RN: Discovery of a potent and selective agonist of the prostaglandin EP4 receptor. Bioorg Med Chem Lett 13: 1129-1132, 2003.

36. Luo R, Kakizoe Y, Wang F, Fan X, Hu S, Yang T, Wang W and Li C: Deficiency of mPGES-1 exacerbates renal fibrosis and inflammation in mice with unilateral ureteral obstruction. Am J Physiol Renal Physiol 312: F121-F133, 2017.

37. Carboneau BA, Allan JA, Townsend SE, Kimple ME, Breyer RM and Gannon M: Opposing effects of prostaglandin E2 receptors EP3 and EP4 on mouse and human $\beta$-cell survival and proliferation. Mol Metab 6: 548-559, 2017.

38. Quan Y, Jiang J and Dingledine R: EP2 receptor signaling pathways regulate classical activation of microglia. J Biol Chem 288 9293-9302, 2013.

39. Wang F, Lu X, Peng K, Du Y, Zhou SF, Zhang A and Yang T: Prostaglandin E-prostanoid4 receptor mediates angiotensin II-induced (pro)renin receptor expression in the rat renal medulla. Hypertension 64: 369-377, 2014.

40. Machado-Carvalho L, Torres R, Perez-Gonzalez M, Alobid I, Mullol J, Pujols L, Roca-Ferrer J and Picado C: Altered expression and signalling of EP2 receptor in nasal polyps of AERD patients: Role in inflammation and remodelling. Rhinology 54: 254-265, 2016

41. Tanaka T, Saotome M, Katoh H, Satoh T, Hasan P, Ohtani H, Satoh H, Hayashi $\mathrm{H}$ and Maekawa Y: Glycogen synthase kinase- $3 \beta$ opens mitochondrial permeability transition pore through mitochondrial hexokinase II dissociation. J Physiol Sci 68: 865-871, 2018

42. Miura T and Tanno M: Mitochondria and GSK-3beta in cardioprotection against ischemia/reperfusion injury. Cardiovasc Drugs Ther 24: 255-263, 2010.

43. Bolli R, Dawn B and Xuan YT: Role of the JAK-STAT pathway in protection against myocardial ischemia/reperfusion injury. Trends Cardiovasc Med 13: 72-79, 2003.

44. Gracia-Sancho J, Casillas-Ramirez A and Peralta C: Molecular pathways in protecting the liver from ischaemia/reperfusion injury: A 2015 update. Clin Sci (Lond) 129: 345-362, 2015.

45. Izuishi K, Tsung A, Hossain MA, Fujiwara M, Wakabayashi H, Masaki T, Billiar TR and Maeta $\mathrm{H}$ : Ischemic preconditioning of the murine liver protects through the Akt kinase pathway. Hepatology 44: 573-580, 2006.

46. Cao CM, Zhang Y, Weisleder N, Ferrante C, Wang X, Lv F, Zhang Y, Song R, Hwang M, Jin L, et al: MG53 constitutes a primary determinant of cardiac ischemic preconditioning. Circulation 121: 2565-2574, 2010.

47. Centurion SA, Centurion LM, Souza ME, Gomes MC, Sankarankutty AK, Mente ED and Castro e Silva O: Effects of ischemic liver preconditioning on hepatic ischemia/reperfusion injury in the rat. Transplant Proc 39: 361-364, 2007. 
48. Varela AT, Simoes AM, Teodoro JS, Duarte FV, Gomes AP, Palmeira CM and Rolo AP: Indirubin-3'-oxime prevents hepatic I/R damage by inhibiting GSK-3beta and mitochondrial permeability transition. Mitochondrion 10: 456-463, 2010.

49. Beurel E, Grieco SF and Jope RS: Glycogen synthase kinase-3 (GSK3): Regulation, actions, and diseases. Pharmacol Ther 148 114-131, 2015.

50. Gross ER, Hsu AK and Gross GJ: GSK3beta inhibition and K(ATP) channel opening mediate acute opioid-induced cardioprotection at reperfusion. Basic Res Cardiol 102: 341-349, 2007.

51. Gross ER, Hsu AK and Gross GJ: The JAK/STAT pathway is essential for opioid-induced cardioprotection: JAK2 as a mediator of STAT3, Akt, and GSK-3 beta. Am J Physiol Heart Circ Physiol 291: H827-H834, 2006.

52. Lecour S: Activation of the protective survivor activating factor enhancement (SAFE) pathway against reperfusion injury: Does it go beyond the RISK pathway? J Mol Cell Cardiol 47: 32-40, 2009.

53. Wang Y, Shen J, Xiong X, Xu Y, Zhang H, Huang C, Tian Y, Jiao C, Wang $X$ and Li X: Remote ischemic preconditioning protects against liver ischemia-reperfusion injury via heme oxygenase-1-induced autophagy. PLoS One 9: e98834, 2014.
54. Yang J, Wang Y, Sui M, Liu F, Fu Z and Wang QX: Tri-iodothyronine preconditioning protects against liver ischemia reperfusion injury through the regulation of autophagy by the MEK/ERK/mTORC1 axis. Biochem Biophys Res Commun 467: 704-710, 2015.

55. Yu J, Wang L, Akinyi M, Li Y, Duan Z, Zhu Y and Fan G: Danshensu protects isolated heart against ischemia reperfusion injury through activation of Akt/ERK1/2/Nrf2 signaling. Int J Clin Exp Med 8: 14793-14804, 2015.

This work is licensed under a Creative Commons Attribution-NonCommercial-NoDerivatives 4.0 International (CC BY-NC-ND 4.0) License. 